\title{
PRIVATIZATION POLICIES BY NATIONAL AND REGIONAL GOVERNMENTS
}

Francisco Martínez-Sánchez (University of Murcia)

Data de publicació: 29/VII/2013

\section{CÀTEDRA PASQUAL MARAGALL D'ECONOMIA I TERRITORI}

\section{COL·LECCIÓ DE DOCUMENTS DE TREBALL}
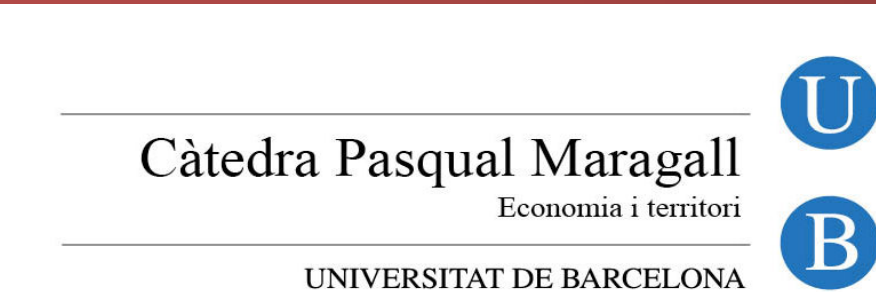

Entitat col·laboradora:

Santander

UNIVERSIDADES 


\title{
Privatization Policies by National and Regional Governments*
}

\author{
Francisco Martínez-Sánchez ${ }^{\dagger}$ \\ University of Murcia
}

July 26, 2013

\begin{abstract}
In order to analyze the privatization policies undertaken by the national and regional governments, we consider a horizontal differentiation model with price competition in which a country consists of two regions of different sizes. We show that public-sector intervention by either the national or regional government is essential for achieving the social optimum, because a private duopoly does not achieve the social optimum. However, not all public interventions in firms are better than the private duopoly. On the other hand, the preferences of consumers and firms about privatization policy are completely opposite. Finally, the privatization policies of regional governments are completely opposite from one region to the other, and do not coincide with that of the national government. Overall, this paper shows that the relative size of regions is an important feature in the design of the privatization policies implemented by national and regional governments.
\end{abstract}

Keywords: Horizontal Differentiation, National and Regional Governments, Mixed Duopoly, Region Size, Partial Privatization

JEL classification: H42, L13, L32, L33, R59

*I acknowledge financial support from the Spanish Ministerio de Economía y Competitividad under Project ECO201019830 and from the Pasqual Maragall Chair. Any remaining errors are mine alone.

${ }^{\dagger}$ Departamento de Métodos Cuantitativos para la Economía y la Empresa, Universidad de Murcia, 30100 Murcia, Spain. E-mail: fms@um.es 


\section{Introduction}

In the eighties the British government began a wave of privatization that was echoed across the world in the following years. Bortolotti et al. (2003) empirically show that privatization takes place typically in wealthy democracies with high public debt, but endowed with deep and liquid stock markets. ${ }^{1}$ They show that legal institutions are also important, in the sense that the law should provide protection for private investment. However, at the end of 2000, governments retained control of two-thirds of privatized firms. In civil law countries, governments tend to retain large ownership positions, whereas in common law countries they typically use golden shares. To put it another way, governments hold more influence over privatized firms in countries with proportional electoral rules and with a centralized system of political authority (Bortolotti and Faccio (2009)). Thus, in the current recession, which affects to most of the countries in the world, a new wave of privatization across the world can be expected, in which the local governments in each country may play an important role. Therefore, it is interesting to analyze strategic interaction at the privatization stage between local governments and the government of the nation to which they belong.

In this paper I develop a model that analyzes strategic interaction between different tiers of government and its consequences on the markets, without neglecting a welfare analysis. Given the presence of firms owned by national and regional governments in many industries, the insights behind the paper can be incorporated into the analysis of different industries, e.g. the airport sector (Albalate et al. (2012) and Matsumura and Matsushima (2012)), the broadcasting market (Bel and Domènech (2009) and González-Maestre and Martínez-Sánchez (2010, 2012)), hospital markets (Brekke et al. (2008), Aiura and Sanjo (2010) and Aiura (2013)), the university system (De Fraja and Valbonesi (2012) and Cremer and Maldonado (2013)), and the development of public facilities (Takahashi (2004)) among others.

The question of whether it is advisable to privatize public firms has been widely analyzed previously. In a seminal paper that assumes quantity competition and homogenous goods, De Fraja and Delbono (1989) show that the existence of a public firm is socially desirable if the number of firms is low enough. However, I consider horizontal product differentiation as in Cremer et al. (1991). They show that it is only when the total number of firms is two or at least six that a mixed oligopoly with one public firm is socially preferable to a private oligopoly. Following Matsumura (1998), I allow partial privatization, so a partially public-owned firm takes both profits and welfare into consideration. Matsumura (1998) analyzes a duopoly model with quantity competition and finds that neither full privatization nor full nationalization is optimal. As in my model, recent research has focused on analyzing privatization policies in horizontal product differentiation models with price competition. For instance, Kumar and Saha (2008) show that unless public ownership exceeds a critical level, maximal differentiation continues to hold and social welfare does not improve with public ownership. Sanjo (2009) analyses simultaneous price choice and sequential price choice and shows that the degree of privatization of a publicly owned firm influences social welfare in a mixed duopoly market. From this last paper, Martínez-Sánchez (2011)

\footnotetext{
${ }^{1}$ This result is also supported by Albalate et al. (2012), who find that it is more likely for airports to be privatized in countries with higher public debt.
} 
shows that in the location game, in which firms set prices simultaneously, social welfare depends on the degree of privatization and is only maximized if the partially privatized firm is a fully publicly owned firm.

Previous papers have considered that public firms are owned by national governments that are concerned for the social welfare of their countries. Thus, they omit firms owned by regional governments that are concerned only for the social welfare of their regions. However, such firms are present in many sectors: the airport sector (Albalate et al. (2012)), the broadcasting market (Bel and Domènech (2009)), hospital markets (Aiura (2013)), the university system (De Fraja and Valbonesi (2012)), the development of public facilities (Takahashi (2004)), etc. My model incorporates regional public firms and analyzes the strategic interaction between them, the government of the country to which they belong and private owners. A recent paper by Tomaru and Nakamura (2012) studies a mixed oligopoly model with quantity competition in a country comprised of two regions. They find that when the national and regional governments independently consider whether to privatize their respective public firms, only the state-owned public firm should be privatized. A paper with features similar to mine is Inoue et al. (2012), in which a regional public firm competes against a private firm. They allow firms to choose their location and prices, but they do not allow partial privatization of the regional public firm. Finally, they show the existence of two types of equilibrium: i) the regional public and private firms locate in different regions; and ii) both firms locate in the same region.

My paper is related to the literature on the privatization policies of national governments in an international context. Bárcena-Ruiz and Garzón (2005a, 2005b) analyze strategic interaction between governments when they decide whether to privatize their publicly-owned firms. They consider two equal countries that form a single market in which there is free trade and firms produce a homogeneous good and decide its output level. ${ }^{2}$ Bárcena-Ruiz and Garzón (2005b) find that when the marginal cost of the publicly-owned firms takes an intermediate value, each government wants it to be the government of the other country that privatizes its publicly-owned firm. In addition, Bárcena-Ruiz and Garzón (2005a) includes the existence of a supra-national authority, whose goal is to maximize social welfare in both countries. They show that if the supra-national authority decides whether or not to privatize public firms, the aggregate politically weighted welfare is no less than if the decision is taken by the governments.

A feature of the aforementioned papers that consider horizontal differentiation is that consumers are uniformly distributed across a linear segment. However, I break with this assumption here. Previously, Calvó-Armengol and Zenou (2002) examine the importance of the distribution of consumers in Hotelling's circle in a comparison between the optimal and market equilibrium levels of diversity. They find that when most consumers are located very close to the firms, the result of Salop -that the equilibrium number of firms is larger than the optimal one- can be reversed. Benassi et al. (2006) use a trapezoid distribution and show that overall more concentrated incomes imply stronger product differentiation. Recently, Gabszewicz and Wauthy (2012) have developed a new variant of the Hotelling model in which the segment where consumers are distributed is divided into two, so there are two "natural" markets with

\footnotetext{
${ }^{2}$ Bárcena-Ruiz and Garzón (2005a, 2005b) do not allow partial privatization by governments.
} 
different sizes. In a private duopoly, they show that equilibrium prices increase whenever the disparity of consumers decreases.

In short, I analyze the privatization policies undertaken by national and regional governments, under which they have the option to partially privatize firms. To that end I consider a horizontal differentiation model with price competition in which a country is divided into two regions. Following Gabszewicz and Wauthy (2012), I assume that one region is more densely populated. We show that public intervention by either the national or regional government is essential for achieving the social optimum, because the private duopoly does not achieve the social optimum. However, not all public interventions in firms are better than the private duopoly. On the other hand, the preferences of consumers and firms about market structures are completely opposite: consumers prefer the intervention regional governments while firms prefer the intervention of the national government in the firm located in the smaller region. Finally, the preferences of the two regional governments about market structures are also completely opposite and do not coincide with that of the national government.

The paper is organized as follows. Section 2 describes the model formally. Sections 3,4 and 5 consider the regional duopoly, the national mixed duopoly and the private duopoly, respectively. The equilibrium of these duopolies is analyzed in Section 6. Regional mixed duopolies are analyzed in Section 7. Section 8 provides a social welfare analysis with all the market structures developed in the paper. Section 9 concludes.

\section{The Model}

A unit mass of consumers is distributed in the $[0,1]$ interval, which represents the location of the consumers in a country which is divided into two regions: $[0,1 / 2]$, which is referred to here as Region 0 , and $[1 / 2,1]$ which is referred to as Region 1. It is assumed that the regions have different population densities (or relative sizes). In particular, with no loss of generality, the density of Region 0 is $\mu \in(0,1 / 2)$ and that of Region 1 is $1-\mu$, as in Gabszewicz and Wauthy (2012), which means that most consumers are located in Region 1 . There are two firms that sell a single product and are located at the two endpoints of the unit interval $[0,1]$ : one is located at zero and indexed by 0 and the other is located at one and indexed by 1 . Notice that firm 0 is located in Region 0 and firm 1 is located in Region 1 . It is assumed that each consumer can buy at most one unit of the product. Thus, the utility of the consumer located at $x$ is:

$$
U(x)=\left\{\begin{array}{cc}
v-x-p_{0} & \text { if he buys from firm } 0 \\
v-(1-x)-p_{1} & \text { if he buys from firm } 1
\end{array}\right.
$$

where $v$ represents the consumer's utility obtained from buying from his/her location, $p_{i}$ represents the price of the product $i=0,1$, and $x$ and $1-x$ represent the disutility from not buying from his/her location if he/she buys from firm 0 and firm 1 , respectively. Thus, consumers located in $[0,1 / 2]$ prefer to buy the product offered by firm 0 than that offered by firm 1 at equal prices, and conversely consumers located in $[1 / 2,1]$ prefer product 1 to product 0 at equal prices. Since $\mu \in(0,1 / 2)$, most consumers prefer 
to buy from firm 1 than from firm 0 at equal prices. It is assumed that $v$ is high enough for all consumers to buy at least from one firm. From the utility function (1), it is possible to find the consumer who is indifferent between buying from firm 0 and firm 1, which is given by:

$$
\widehat{x}\left(p_{0}, p_{1}\right)=\frac{1}{2}+\frac{p_{1}-p_{0}}{2} .
$$

In order to obtain the demand functions of the two firms, two cases must be analyzed: (i) when the indifferent consumer is located in Region $0, \widehat{x}\left(p_{0}, p_{1}\right)<1 / 2$, and (ii) when he/she is located in Region $1, \widehat{x}\left(p_{0}, p_{1}\right)>1 / 2$. Thus, if $p_{0}>p_{1}$, then $\widehat{x}\left(p_{0}, p_{1}\right)<1 / 2$, which means that there are some consumers in Region 0 that buy products from the firm located in Region 1 . In particular, $\left[\widehat{x}\left(p_{0}, p_{1}\right), 1 / 2\right]$. On the other hand, if $p_{0}<p_{1}$, then $\widehat{x}\left(p_{0}, p_{1}\right)>1 / 2$, which means that there are some consumers in Region 1 that buy from firm 0 . In particular, $\left[1 / 2, \widehat{x}\left(p_{0}, p_{1}\right)\right]$. Thus, taking into account that the densities of the regions are different, the demand functions are:

$$
\begin{aligned}
& D_{0}\left(p_{0}, p_{1}\right)=\left\{\begin{array}{cc}
\frac{\mu+(1-\mu)\left(p_{1}-p_{0}\right)}{2} & \text { if } p_{0} \leq p_{1} \\
\frac{\mu\left(1+p_{1}-p_{0}\right)}{2} & \text { if } p_{0} \geq p_{1}
\end{array}\right. \\
& D_{1}\left(p_{0}, p_{1}\right)=\left\{\begin{array}{cc}
\frac{(1-\mu)\left(1-p_{1}+p_{0}\right)}{2} & \text { if } p_{0} \leq p_{1} \\
\frac{1-\mu-\mu\left(p_{1}-p_{0}\right)}{2} & \text { if } p_{0} \geq p_{1}
\end{array}\right.
\end{aligned}
$$

It is assumed that the fixed cost of developing a product and the marginal cost are zero. Thus, the profit function of each firm is:

$$
\begin{aligned}
& \pi_{0}\left(p_{0}, p_{1}\right)=\left\{\begin{array}{cc}
p_{0} \frac{\mu+(1-\mu)\left(p_{1}-p_{0}\right)}{2} & \text { if } p_{0} \leq p_{1} \\
p_{0} \frac{\mu\left(1+p_{1}-p_{0}\right)}{2} & \text { if } p_{0} \geq p_{1}
\end{array}\right. \\
& \pi_{1}\left(p_{0}, p_{1}\right)=\left\{\begin{array}{cc}
p_{1} \frac{(1-\mu)\left(1-p_{1}+p_{0}\right)}{2} & \text { if } p_{0} \leq p_{1} \\
p_{1} \frac{1-\mu-\mu\left(p_{1}-p_{0}\right)}{2} & \text { if } p_{0} \geq p_{1}
\end{array}\right.
\end{aligned}
$$

A third kind of agent consider here is comprised of regional governments that maximize regional social welfare. The social welfare of Region $i$ is defined as the sum of the profit of the firm profit and the surplus of the consumers located in Region $i$, i.e. $W_{i}=\pi_{i}+C S_{i} i=0,1$, where

$$
\begin{gathered}
C S_{0}=\left\{\begin{array}{cc}
\mu \int_{0}^{\frac{1}{2}}\left(v-x-p_{0}\right) d x & \text { if } p_{0} \leq p_{1} \\
\mu \int_{0}^{\widehat{x}}\left(v-x-p_{0}\right) d x+\mu \int_{\widehat{x}}^{\frac{1}{2}}\left(v-(1-x)-p_{1}\right) d x & \text { if } p_{0} \geq p_{1} .
\end{array}\right. \\
C S_{1}=\left\{\begin{array}{cc}
(1-\mu)\left(\int_{\frac{1}{2}}^{\widehat{x}}\left(v-x-p_{0}\right) d x+\int_{\widehat{x}}^{1}\left(v-(1-x)-p_{1}\right) d x\right) & \text { if } p_{0} \leq p_{1} \\
(1-\mu) \int_{\frac{1}{2}}^{1}\left(v-(1-x)-p_{1}\right) d x & \text { if } p_{0} \geq p_{1} .
\end{array}\right.
\end{gathered}
$$

In the model proposed here regional governments may become shareholders of the firms located in their regions. Thus, the aims of these firms depend on the composition of their boards because regional government representatives advocate maximizing regional social welfare and private shareholders advocate 
a profit motive. Following Matsumura (1998), it is assumed here that the board of a partially publiclyowned regional firm seeks to maximize a well-balanced mean between its profit and regional social welfare, where the weights are the stakes held in it by the regional government and by private owners. The government of Region $i$ is considered to own a stake of $\alpha_{i} \in[0,1]$ and the private owners $1-\alpha_{i}$ of the partially publicly-owned firm located in Region $i$, so the objective function of partially publicly-owned firms is $\Pi_{i}=\alpha_{i} W_{i}+\left(1-\alpha_{i}\right) \pi_{i} i=0,1$. Notice that full privatization is achieved when $\alpha_{i}=0$. The timing of the game is as follows:

i) in order to maximize regional social welfare, each regional government simultaneously chooses its share in the partially publicly-owned firm located in its region, $\alpha_{i} i=0,1$; and,

ii) finally, firms simultaneously set prices.

In the following section, this game is solved by backward induction.

\section{Regional Duopoly}

From the profit functions of firm 0 and firm 1, (5) and (6), and the consumer surpluses of regions 0 and $1,(7)$ and (8), the expressions for social welfare in each region are found, i.e.:

$$
\begin{gathered}
W_{0}=\pi_{0}+C S_{0}=\left\{\begin{array}{cc}
\frac{4 v \mu-\mu+4(1-\mu) p_{0}\left(p_{1}-p_{0}\right)}{8} & \text { if } p_{0} \leq p_{1} \\
\frac{\mu\left(4 v-1+2\left(p_{1}^{2}-p_{0}^{2}\right)\right)}{8} & \text { if } p_{0} \geq p_{1}
\end{array}\right. \\
W_{1}=\pi_{1}+C S_{1}=\left\{\begin{array}{cc}
\frac{(1-\mu)\left(4 v-2\left(p_{1}^{2}-p_{0}^{2}\right)-1\right)}{8} & \text { if } p_{0} \leq p_{1} \\
\frac{(1-\mu)(4 v-1)+4 \mu p_{1}\left(p_{0}-p_{1}\right)}{8} & \text { if } p_{0} \geq p_{1},
\end{array}\right.
\end{gathered}
$$

Taking into account theses expressions, I maximize the objective functions $\Pi_{0}$ (with respect to $p_{0}$ ) and $\Pi_{1}$ (with respect to $p_{1}$ ), and obtain the firms' reaction functions, which are:

$$
\begin{gathered}
p_{0}\left(p_{1}\right)=\left\{\begin{array}{cl}
\frac{\left(1-\alpha_{0}\right) \mu}{2(1-\mu)}+\frac{p_{1}}{2} & \text { if } p_{0} \leq p_{1} \\
\left(p_{1}+1\right) \frac{1-\alpha_{0}}{2-\alpha_{0}} & \text { if } p_{0} \geq p_{1},
\end{array}\right. \\
p_{1}\left(p_{0}\right)=\left\{\begin{array}{cl}
\left(p_{0}+1\right) \frac{1-\alpha_{1}}{2-\alpha_{1}} & \text { if } p_{0} \leq p_{1} \\
\frac{\left(1-\alpha_{1}\right)(1-\mu)}{2 \mu}+\frac{p_{0}}{2} & \text { if } p_{0} \geq p_{1} .
\end{array}\right.
\end{gathered}
$$

From the intersection of the price reaction function of regional publicly-owned firms, the prices at this stage of the game are found, i.e.:

$$
p_{0}\left(\alpha_{0}, \alpha_{1}\right)=\left\{\begin{array}{ll}
\frac{\mu+1-\alpha_{1}-\mu \alpha_{0}\left(2-\alpha_{1}\right)}{(1-\mu)\left(3-\alpha_{1}\right.} & \text { if } p_{0} \leq p_{1} \\
\frac{\left(1-\alpha_{0}\right)\left(1+\mu-\alpha_{1}+\mu \alpha_{1}\right)}{\mu\left(3-\alpha_{0}\right)} & \text { if } p_{0} \geq p_{1}
\end{array} ; p_{1}\left(\alpha_{0}, \alpha_{1}\right)=\left\{\begin{array}{cl}
\frac{\left(1-\alpha_{1}\right)\left(2-\mu-\mu \alpha_{0}\right)}{\left(3-\alpha_{1}\right)(1-\mu)} & \text { if } p_{0} \leq p_{1} \\
\frac{\left(2-\alpha_{0}\right)\left(1-\alpha_{1}(1-\mu)\right)-\mu}{\mu\left(3-\alpha_{0}\right)} & \text { if } p_{0} \geq p_{1}
\end{array}\right.\right.
$$

Each regional government now maximizes the social welfare of its region, so that by substituting firms' prices (13) in regional social welfare functions (9) and (10), and maximizing these functions with respect 
to $\alpha_{0}$ and $\alpha_{1}$, respectively, the regional governments' reaction functions of the share in the partially publicly-owned firms are found:

$$
\alpha_{0}\left(\alpha_{1}\right)=\left\{\begin{array}{cl}
\frac{5 \mu-1+\alpha_{1}\left(2-4 \mu-\alpha_{1}(1-\mu)\right)}{2 \mu\left(2-\alpha_{1}\right)} & \text { if } p_{0} \leq p_{1} \\
\frac{3 \mu-\mu) \alpha_{1}+1}{2 \mu-(1-\mu)} & \text { if } p_{0} \geq p_{1}
\end{array} ; \alpha_{1}\left(\alpha_{0}\right)=\left\{\begin{array}{cl}
\frac{3(1-\mu)}{3-2 \mu-\mu \alpha_{0}} & \text { if } p_{0} \leq p_{1} \\
\frac{4-5 \mu+\alpha_{0}\left(4 \mu-\mu \alpha_{0}-2\right)}{2\left(2-\alpha_{0}\right)(1-\mu)} & \text { if } p_{0} \geq p_{1}
\end{array}\right.\right.
$$

From the intersection of the above reaction functions and taking into account that $\alpha_{i} \in[0,1]$, the Subgame Perfect Equilibrium (SPE) of this game is obtained, in which each regional government fully owns the firm that is located at its region. As a result, both regional publicly-owned firms set the same price, so the indifferent consumer is located at the border between the two regions, $\widehat{x}^{R}=1 / 2$. Thus, consumers buy the product from the firm located in their region. These results are summarized in Proposition 1.

Proposition 1 In the SPE of the Regional Duopoly, regional governments fully control firms $\left(\alpha_{0}^{R}=\right.$ $\left.\alpha_{1}^{R}=1\right)$ and the prices, indifferent consumer, consumer surplus and social welfare are:

$$
p_{0}^{R}=p_{1}^{R}=0 ; \widehat{x}^{R}=\frac{1}{2} ; C S_{0}^{R}=W_{0}^{R}=\mu W^{R} ; C S_{1}^{R}=W_{1}^{R}=(1-\mu) W^{R} ; C S^{R}=W^{R}=\frac{4 v-1}{8} .
$$

An interesting result is that both firms set the same price at the SPE, although they face markets with different sizes. What is more they set a price of zero and thus do not obtain any revenue. Thus, the regional social welfare coincides with the regional consumer surplus for each region. Moreover, the regional social welfare depends on the population density of the region so that $W_{0}^{R}<W_{1}^{R}$ since $\mu \in(0,1 / 2)$. However, the national social welfare does not depend on the relative sizes of the regions.

Given that firms cannot discriminate on prices according to the location of consumers, the best way of maximizing the regional social welfare is to set the lowest price (which is zero) and maximize the regional consumer surplus.

\section{National Mixed Duopoly}

In order to analyze and compare the results obtained with those of the regional duopoly, I now consider the intervention of the national government as a shareholder of a publicly-owned firm. It is concerned for the social welfare of the country, which is defined as the sum of the social welfare of both regions, $W=W_{0}+W_{1} \cdot{ }^{3}$ Taking into account the regional social welfare functions (9) and (10), the expression of national social welfare is found to be the following:

$$
W=\left\{\begin{array}{cl}
\frac{4 v-1-2(1-\mu)\left(p_{0}-p_{1}\right)^{2}}{8} & \text { if } p_{0} \leq p_{1} \\
\frac{4 v-1-2 \mu\left(p_{0}-p_{1}\right)^{2}}{8} & \text { if } p_{0} \geq p_{1}
\end{array}\right.
$$

In this section the regional governments do not participate in the game. Thus, the partially national publicly-owned firm competes against a private firm that maximizes its profit. The aims of the partially

\footnotetext{
${ }^{3}$ An equivalent definition of national social welfare is: the sum of firms' profits and the consumer surplus, $W=\pi_{0}+$ $\pi_{1}+C S$, where $C S=C S_{0}+C S_{1}$.
} 
publicly-owned firm depend on the composition of its board because the national government's representatives advocate maximizing social welfare and private shareholders advocate a profit motive. It is assumed here that the board of the partially publicly-owned firm seeks to maximize a well-balanced mean between the national social welfare and its profit, where the weights are the stakes held by the government and private owners. I consider that the national government owns a stake of $\alpha \in[0,1]$ of the partially publicly-owned firm and private owners $1-\alpha$, so the objective function of the partially publicly-owned firm is $\Pi_{i}=\alpha W+(1-\alpha) \pi_{i} i=0,1$. Notice that $1-\alpha$ measures the degree of privatization, so full privatization is achieved when $\alpha=0$ and full nationalization when $\alpha=1$.

The timing of the game is as follows: (i) in order to maximize social welfare, the national government chooses the firm in which it is to take a stake; (ii) next, it decides how big a stake to take in that firm, $\alpha$; and (iii) finally, firms simultaneously set prices.

In the following subsections, the subgames in which the national government partially owns firm 0 (subgame 0) and firm 1 (subgame 1) are solved.

\subsection{Subgame 0}

In this subgame, the national government takes a partial stake in firm 0 , so firm 0 maximizes the objective function $\Pi_{0}\left(p_{0}, p_{1}\right)=\alpha W+(1-\alpha) \pi_{0}$, which is given by:

$$
\Pi_{0}\left(p_{0}, p_{1}\right)=\left\{\begin{array}{cl}
\alpha \frac{4 v-1-2(1-\mu)\left(p_{0}-p_{1}\right)^{2}}{8}+(1-\alpha) p_{0} \frac{\mu+(1-\mu)\left(p_{1}-p_{0}\right)}{2} & \text { if } p_{0} \leq p_{1} \\
\alpha \frac{4 v-1-2 \mu\left(p_{0}-p_{1}\right)^{2}}{8}+(1-\alpha) p_{0} \mu \frac{1+p_{1}-p_{0}}{2} & \text { if } p_{0} \geq p_{1} .
\end{array}\right.
$$

Next I solve the third stage, in which firms simultaneously choose prices. Therefore, by maximizing the function (16) with respect to $p_{0}$, the reaction function of the partially publicly-owned firm 0 is obtained, i.e.:

$$
p_{0}\left(p_{1}\right)=\left\{\begin{array}{cl}
\frac{(1-\alpha) \mu}{(2-\alpha)(1-\mu)}+\frac{p_{1}}{2-\alpha} & \text { if } p_{0} \leq p_{1} \\
\frac{1-\alpha}{2-\alpha}+\frac{p_{1}}{2-\alpha} & \text { if } p_{0} \geq p_{1}
\end{array}\right.
$$

Firm 1 is a private firm that aims to maximize the profit function (6). Thus, the reaction function of this firm is:

$$
p_{1}\left(p_{0}\right)=\left\{\begin{array}{cl}
\frac{1}{2}+\frac{p_{0}}{2} & \text { if } p_{0} \leq p_{1} \\
\frac{1-\mu}{2 \mu}+\frac{p_{0}}{2} & \text { if } p_{0} \geq p_{1} .
\end{array}\right.
$$

From the interception of the above reaction functions, I obtain the prices at this stage, which are:

$$
p_{0}(\alpha)=\frac{1+\mu-2 \alpha \mu}{(1-\mu)(3-2 \alpha)} ; p_{1}(\alpha)=\frac{2-\alpha-\mu}{(1-\mu)(3-2 \alpha)} .
$$

Notice that $p_{0} \leq p_{1}$. By substituting the above prices in the social welfare function (15), it can be evaluated at the second stage of this subgame. Thus, the expression of the social welfare is:

$$
W(\alpha)=\frac{4 v(3-2 \alpha)^{2}(1-\mu)+16 \alpha-6 \alpha^{2}-8 \mu^{2}\left(1+\alpha^{2}\right)-4 \alpha \mu(7-4 \mu-3 \alpha)+17 \mu-11}{8(3-2 \alpha)^{2}(1-\mu)}
$$

In order to maximize the social welfare function (19), the government decides to fully nationalize firm 0 , so that $\alpha^{0}=1$. This implies that both firms set the same price. Moreover, there is a multiplicity 


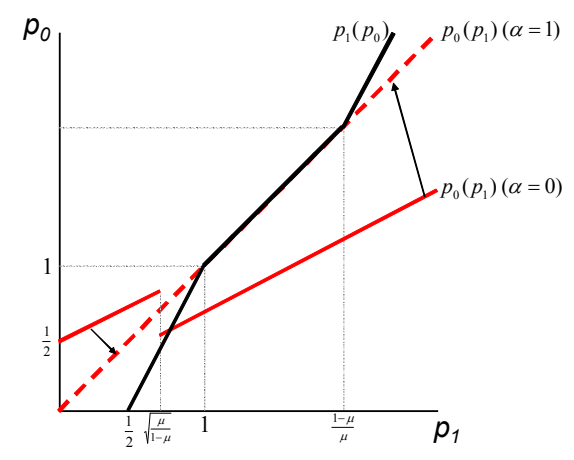

Figure 1: Equilibrium at subgame 0.

of equilibrium prices, although a unique value of welfare is obtained, as can be seen in Figure 1 and Proposition 2:

Proposition 2 In subgame 0 of the National Mixed Duopoly, the national government fully nationalizes firm $0\left(\alpha^{0}=1\right)$, and the prices, indifferent consumer, profits, consumer surplus and welfare are:

$$
p_{0}^{0}=p_{1}^{0} \in\left[1, \frac{1-\mu}{\mu}\right] ; \widehat{x}^{0}=\frac{1}{2} ; \pi_{0}^{0}=\mu \frac{p_{0}}{2} ; \pi_{1}^{0}=(1-\mu) \frac{p_{0}}{2} ; C S^{0}=\frac{4 v-4 p_{0}-1}{8} ; W^{0}=\frac{4 v-1}{8} .
$$

\subsection{Subgame 1}

The national government now takes a stake in firm 1 , so that the objective function of firm 1 is $\Pi_{1}=$ $\alpha W+(1-\alpha) \pi_{1}$. As in the previous subsection, the stage in which firms simultaneously choose prices is solved first. By maximizing the function $\Pi_{1}$ with respect to $p_{1}$, I obtain the reaction function of the partially publicly-owned firm 1 , which is:

$$
p_{1}\left(p_{0}\right)=\left\{\begin{array}{cc}
\frac{1-\alpha}{2-\alpha}+\frac{p_{0}}{2-\alpha} & \text { if } p_{0} \leq p_{1} \\
\frac{(1-\mu)(1-\alpha)}{\mu(2-\alpha)}+\frac{p_{0}}{2-\alpha} & \text { if } p_{0} \geq p_{1}
\end{array}\right.
$$

Firm 0 is private, so it maximizes the profit function (5) and its reaction function is:

$$
p_{0}\left(p_{1}\right)=\left\{\begin{array}{cl}
\frac{\mu}{2(1-\mu)}+\frac{p_{1}}{2} & \text { if } p_{0} \leq p_{1} \\
\frac{1}{2}+\frac{p_{1}}{2} & \text { if } p_{0} \geq p_{1} .
\end{array}\right.
$$

Given that firm 0 's reaction function is discontinuous at $\sqrt{\mu /(1-\mu)}$, it is possible that the two reaction functions may not intercept as can be seen in Figure 2. In particular, if $\alpha>\bar{\alpha}=1-\frac{1}{2} \sqrt{\frac{\mu}{1-\mu}}$, the two reaction functions do not intersect. Otherwise, if $\alpha \leq \bar{\alpha}$, they intercept and the prices are: ${ }^{4}$

$$
p_{0}=\frac{1-\alpha+\mu}{(1-\mu)(3-2 \alpha)} ; p_{1}=\frac{2-\mu-2 \alpha(1-\mu)}{(1-\mu)(3-2 \alpha)} .
$$

\footnotetext{
${ }^{4}$ Notice that $p_{1}=\frac{2-\mu-2 \alpha(1-\mu)}{(1-\mu)(3-2 \alpha)} \geq \sqrt{\frac{\mu}{1-\mu}}$ if and only if $\alpha \leq \bar{\alpha}=1-\frac{1}{2} \sqrt{\frac{\mu}{1-\mu}}$.
} 


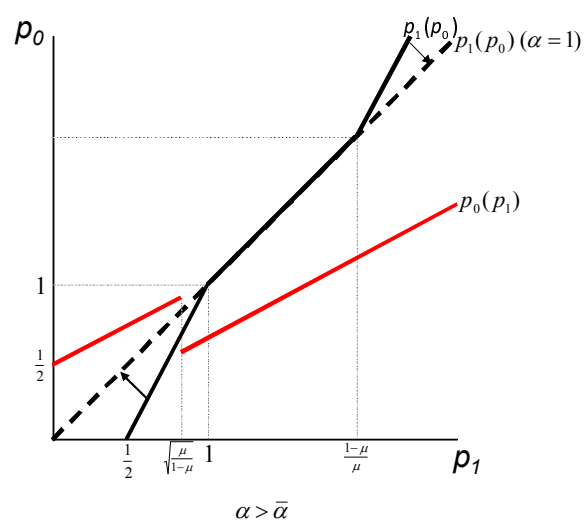

Figure 2: Equilibrium at subgame 1.

Notice that $p_{0} \leq p_{1}$. By substituting the previous prices (23) in the social welfare function (15), it is evaluated at the second stage, which coincides with that obtained in previous section, that is (19). Therefore, taking into account that the social welfare function (19) is increasing when $\alpha<1$, there is no solution when $\alpha>\bar{\alpha}$, and $\bar{\alpha}<1$ (since $\mu \in(0,1 / 2)$ ), I find that the national government partially privatize firm 1 , as shown in the following proposition:

Proposition 3 In subgame 1 of the National Mixed Duopoly, the national government takes a stake in firm 1 at $\alpha^{1}=\bar{\alpha}$ level.

\subsection{Government: firm 0 or 1}

Next, I look at which firm the government must take a stake in from a social point of view. The above subsections show that the government fully nationalizes firm 0 or partially nationalizes firm 1 . Notice that when the government decides its stake in each firm, it faces the same objective function in both subgames. In particular, it faces the function (19). Given that the social welfare function (19) is increasing when $\alpha<1$, and $\alpha^{1}<\alpha^{0}=1$, the government takes a stake in firm 0 . Therefore, the government fully nationalizes firm 0 in the SPE of the complete game, which is shown in Proposition 4.

Proposition 4 In the SPE for National Mixed Duopoly, the government fully nationalizes firm 0, so that the prices, indifferent consumer, profits, consumer surplus and welfare are:

$$
\begin{aligned}
p_{0}^{N} & =p_{1}^{N}=p^{N} \in\left[1, \frac{1-\mu}{\mu}\right] ; \widehat{x}^{N}=\frac{1}{2} ; \pi_{0}^{N}=\frac{\mu p^{N}}{2} ; \pi_{1}^{N}=\frac{(1-\mu) p^{N}}{2} ; C S_{0}^{N}=\mu C S^{N} ; \\
C S_{1}^{N} & =(1-\mu) C S^{N} ; W_{0}^{N}=\mu W^{N} ; W_{1}^{N}=(1-\mu) W^{N} ; C S^{N}=\frac{4 v-4 p^{N}-1}{8} ; W^{N}=\frac{4 v-1}{8} .
\end{aligned}
$$

In contrast to the regional duopoly model, a multiplicity of equilibrium prices is obtained. Thus, both firms get positive profits, unlike the regional duopoly model. This last result is due to the existence of a rival private firm whose profit is included in the objective function of the publicly-owned firm, while 
in the regional duopoly both firms are owned by regional governments that are not concerned about the rival firm's profit. A strange result is that in the national mixed duopoly both firms set the same price at the SPE, although they have different objective functions.

Notice that the national producer surplus, defined as $\pi^{N}=\pi_{0}^{N}+\pi_{1}^{N}$, does not depend on $\mu$, although it does depend positively on prices. However, the profit of each firm is a fraction of the producer surplus, which is equal to the population density of the region in which it is located. Since $\mu \in(0,1 / 2)$, I find that $\pi_{0}^{N}<\pi_{1}^{N}$. On the consumers side a similar result is observed. In particular, the national consumer surplus does not depend on $\mu$ and the consumer surplus of each region is a fraction of the national consumer surplus, which is equal to the population density of the region in which consumers are located. Since $\mu \in(0,1 / 2), C S_{0}^{N}<C S_{1}^{N}$. Thus, the regional social welfare depends on $\mu$ so that $W_{0}^{N}<W_{1}^{N}$, and the national social welfare does not depend on the relative sizes of the regions $(\mu)$.

\section{Private Duopoly}

We now consider the private duopoly in which the aim of both firms is to maximize their profits. Given that the market in Region 1 is bigger, the competition between firms focuses on consumers in Region 1. Thus, the firm located in Region 0 sets a lower price than firm 1 in order to sell its product in Region 1. This contrasts with the result that firms set the same price obtained when they are publicly-owned, regardless of whether they are national or regional. The private duopoly is analyzed by Gabszewicz and Wauthy (2012), and their result is reproduced here as follows:

Result 1 (Gabszewicz and Wauthy (2012)) Assume $\mu \in(0,1 / 2)$, there is a unique Nash equilibrium given by

$$
p_{0}^{P}=\frac{1+\mu}{3(1-\mu)} \text { and } p_{1}^{P}=\frac{2-\mu}{3(1-\mu)} .
$$

From Gabszewicz and Wauthy's result, the equilibrium values of the indifferent consumer, firms' profits, consumer surplus and social welfare at both national and regional level can be found. Given that $p_{0}^{P}<p_{1}^{P}$, I find that the indifferent consumer is located in Region 1, i.e. $\widehat{x}^{P}>1 / 2$, which means that some consumers in Region 1 buy from firm 0 . These additional results are shown in Proposition 5.

Proposition 5 In the SPE of the Private Duopoly, the indifferent consumer, firms' profits, consumer surplus and social welfare are:

$$
\begin{aligned}
\widehat{x}^{P} & =\frac{4-5 \mu}{6(1-\mu)} ; \pi_{0}^{P}=\frac{(\mu+1)^{2}}{18(1-\mu)} ; \pi_{1}^{P}=\frac{(2-\mu)^{2}}{18(1-\mu)} ; C S_{0}^{P}=\frac{\mu(12 v(1-\mu)-\mu-7)}{24(1-\mu)} ; \\
C S_{1}^{P} & =\frac{36 v(1-\mu)^{2}+\mu(46-13 \mu)-31}{72(1-\mu)} ; C S^{P}=\frac{36 v(1-\mu)+25 \mu-16 \mu^{2}-31}{72(1-\mu)} \\
W_{0}^{P} & =\frac{36 v \mu(1-\mu)-13 \mu+\mu^{2}+4}{72(1-\mu)} ; W_{1}^{P}=\frac{12 v(1-\mu)^{2}+10 \mu-3 \mu^{2}-5}{24(1-\mu)} \\
W^{P} & =\frac{36 v(1-\mu)+17 \mu-8 \mu^{2}-11}{72(1-\mu)}
\end{aligned}
$$



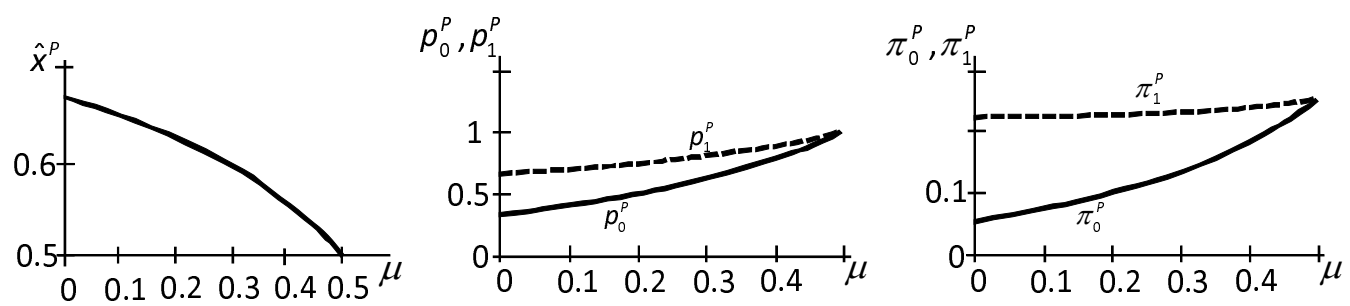

Figure 3: Indifferent Consumer, Prices and Profits.

Firm 0 sets an aggressive price strategy because there are fewer consumers near its location. To maximize profits, it therefore tries to sell to consumers located in Region 1, although they face a higher transport cost if they buy from firm 0 . On the other hand, firm 1 has more consumers, whose transport cost is higher when they buy from the rival firm 0 . Thus, it can set a higher price without losing many consumers, so that $\pi_{0}^{P}<\pi_{1}^{P}$ for $\mu \in(0,1 / 2)$. The stronger competition for Region 1's consumers and larger size of Region 1 cause $C S_{0}^{P}<C S_{1}^{P}$. Therefore, $W_{0}^{P}<W_{1}^{P}$. These last results coincide with those of the previous sections.

A decrease in $\mu$ means a bigger gap in size between regions, which leads firm 0 to be more aggressive in prices in order to enter the larger market of Region 1. In particular, as $\mu$ decreases, firm 0 sets a lower price than firm 1, so the indifferent consumer is located far from the centre $\left(\widehat{x}^{P}\right.$ is decreasing in $\left.\mu\right)$. Thus, in order to avoid losing more consumers, firm 1 decreases prices but less than firm 0, although the size of region 1 increases. Therefore, the firm's profits decrease for the more aggressive price strategy. These results are summarized in the following proposition and Figure 3:

Proposition 6 In the SPE of the private duopoly:

i) $\widehat{x}^{P}$ is decreasing in $\mu$,

ii) $p_{0}^{P}, p_{1}^{P}, \pi_{0}^{P}$ and $\pi_{1}^{P}$ are increasing in $\mu$,

iii) $\frac{\partial p_{0}^{P}}{\partial \mu}>\frac{\partial p_{1}^{P}}{\partial \mu}$ and $\frac{\partial \pi_{0}^{P}}{\partial \mu}>\frac{\partial \pi_{1}^{P}}{\partial \mu}$.

\section{Equilibrium Analysis}

In the private duopoly, firms set different prices so that consumers' choice depends on their location and on prices. This implies a social loss because some consumers do not buy from the nearer firm, although they do buy the cheapest product. In particular, in the private duopoly some consumers in Region 1 buy from firm 0 , which implies higher transport costs for consumers. Moreover, there are more consumers in Region 1. These facts explain why it is found that the privatization of publicly-owned firms is not optimal, as can be concluded from the relationship (25). This result holds regardless of whether the 
publicly-owned firms are owned by the national or the regional governments.

$$
W^{P}<W^{N}=W^{R} .
$$

In both regional and national mixed duopolies, firms set the same price and avoid the welfare loss generated by the high transport costs for consumers in the private duopoly. However, although social welfare is the same in both market structures, the causes are different. In the regional duopoly both firms set a price of zero, which maximizes the consumer surplus and social welfare, although the two regional firms do not obtain profits. On the other hand, in the national mixed duopoly firms set a higher price than in other market structures, which is strange because a publicly-owned firm normally sets lower prices. These high prices imply that the consumer surplus is lowest in the national mixed duopoly, while the producer surplus $\left(\pi=\pi_{0}+\pi_{1}\right)$ is highest, as can be seen in the following relationship:

$$
\begin{gathered}
p_{0}^{R}=p_{1}^{R}=0<p_{0}^{P}<p_{1}^{P}<1 \leq p_{0}^{N}=p_{1}^{N} \\
C S^{N}<C S^{P}<C S^{R} \\
\pi^{R}<\pi^{P}<\pi^{N}
\end{gathered}
$$

I now evaluate social welfare from a regional perspective. From (26) two interesting results can be observed: i) Region 0 prefers the private duopoly, while Region 1 does not; and ii) like the national government, both regional governments are indifferent to the level of public intervention, i.e. they are indifferent between the national mixed duopoly and the regional duopoly. The first result arises because firm 0 sets a low enough price in the private duopoly to obtain high demand (some consumers located in Region 1 buy from firm 0) and the transport cost of Region 0's consumers does no change with respect to other market structures. Thus, Region 0 prefers the private duopoly. However, in Region 1 consumers bear a higher transport cost and firm 1's profit is not too high, so Region 1 prefers (national and regional) government intervention in the market. ${ }^{5}$ This second result also arises because both firms set the same price in the national mixed duopoly and the regional duopoly, so consumers' choice only depends on their location. Thus, consumers buy from the firm nearer their location and the price level does not affect the level of social welfare. However, it does affect welfare distribution between consumers and firms. Therefore, both regional governments are indifferent between the national mixed duopoly and the regional duopoly, although consumers and firms are not in agreement. In particular, as can be seen from relationships (27) and (28), consumers prefer the regional duopoly but firms do not. This is because firms set their highest prices in the national mixed duopoly and their lowest prices in the regional duopoly.

$$
\begin{gathered}
W_{0}^{N}=W_{0}^{R}<W_{0}^{P} \text { and } W_{1}^{N}=W_{1}^{R}>W_{1}^{P} \\
C S_{i}^{N}<C S_{i}^{P}<C S_{i}^{R} i=0,1 \\
\pi_{0}^{R}=0<\pi_{0}^{P} \lesseqgtr \pi_{0}^{N} \text { and } \pi_{1}^{R}=0<\pi_{1}^{P}<\pi_{1}^{N}
\end{gathered}
$$

\footnotetext{
${ }^{5}$ It can be checked that $\pi_{0}^{P}<\pi_{0}^{N}$ if $\mu>1 / 5$. Otherwise, it is possible that $\pi_{0}^{P} \geq \pi_{0}^{N}$.
} 


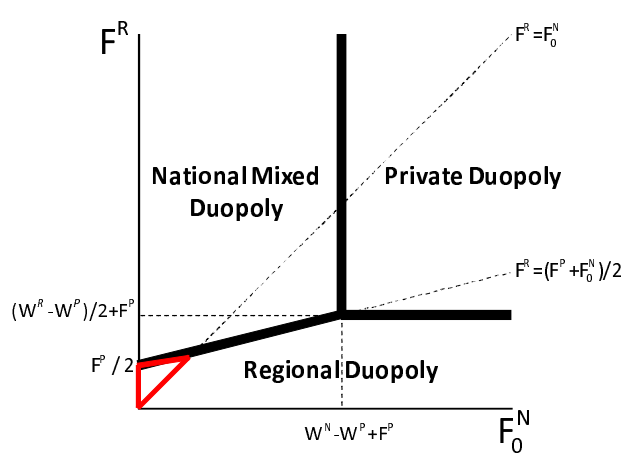

Figure 4: Optimal Privatization Policy.

\subsection{The Fixed Cost of Developing a Product}

This subsection extends the social welfare analysis to consider the fixed cost of developing a product, which is denoted by $F_{i}^{j}$ for firm $i=0,1$ in the market structure $j=N, P, R$. Thus, the social welfare in the national mixed, regional and private duopolies are:

$$
\bar{W}^{N}=W^{N}-F_{0}^{N}-F_{1}^{N} ; \bar{W}^{R}=W^{R}-F_{0}^{R}-F_{1}^{R} ; \bar{W}^{P}=W^{P}-F_{0}^{P}-F_{1}^{P} .
$$

For the sake of clarify in the exposition of the results, the following assumption is made:

Assumption 1 Private firms bear the same fixed cost of developing a product independently of their locations and of the ownership of their rival, i.e. $F_{0}^{P}=F_{1}^{P}=F_{1}^{N}=F^{P}$; and regional firms bear the same fixed cost of developing a product independently of their locations, $F_{0}^{R}=F_{1}^{R}=F^{R}$.

As can be seen in Figure 4, the fixed cost borne by firms is relevant in the privatization policies of national and regional governments. In particular, privatization is found to be socially optimal when fixed costs of national and regional publicly-owned firms are high enough, and not otherwise. Thus, the existence of a national publicly-owned firm is socially optimal when its fixed cost is low enough, and a regional duopoly is optimal when the fixed costs of regional publicly-owned firms are low enough. These results are summarized in the following proposition:

Proposition 7 Under Assumption 1, the optimal privatization policy is:

i) privatization if $F_{0}^{N}>W^{N}-W^{P}+F^{P}$ and $F^{R}>\left(W^{R}-W^{P}\right) / 2+F^{P}$,

ii) the existence of a national publicly-owned firm 0 if $F_{0}^{N}<W^{N}-W^{P}+F^{P}$ and $F^{R}>\left(F_{0}^{N}+F^{P}\right) / 2$, and,

iii) a regional duopoly if $F^{R}<\min \left\{\left(F_{0}^{N}+F^{P}\right) / 2,\left(W^{R}-W^{P}\right) / 2+F^{P}\right\}$.

An interesting result is shown in Figure 4: the regional duopoly is socially optimal in the red area, although the fixed cost is lower for the national publicly-owned firm than the regional one. This is because 
there is a private firm in the national mixed duopoly, which bears a higher fixed cost than the regional publicly-owned firms. ${ }^{6}$

\section{Regional Mixed Duopolies}

As can be seen in Section 6, Region 1 prefers the intervention of national or regional governments, while Region 0 prefers there to be no public intervention. Thus, there are opposed interests between the two regions, which raises the question of whether there are other duopoly regimes that would improve welfare in both regions at the same time. In order to answer this question, the following regional mixed duopolies are considered:

i) regional partially publicly-owned firm 0 competes against private firm 1 (R0);

ii) regional partially publicly-owned firm 1 competes against private firm 0 (R1);

iii) regional partially publicly-owned firm 0 competes against national partially publicly-owned firm $1(\mathrm{R} 0 \mathrm{~N})$; and

iv) national partially publicly-owned firm 0 competes against regional partially publicly-owned firm $1(\mathrm{R} 1 \mathrm{~N})$.

\subsection{Regional Publicly-owned Firm 0 vs. Private Firm 1 (R0)}

In this subsection, the government of Region 0 takes a partial stake in firm 0 , so the aim of firm 0 is to maximize the objective function $\Pi_{0}=\alpha_{0} W_{0}+\left(1-\alpha_{0}\right) \pi_{0}$, where $\alpha_{0}$ represents the stake of the government of Region 0 in firm 0 . This firm competes against the private firm 1 . The timing of the game is: i) the regional government chooses the stake in firm 0 that maximizes the social welfare of Region 0 ; and finally, ii) firms simultaneously set prices. This game is now solved by backward induction.

As can be seen in Section 3, the reaction function of firm 0 is (11). On the other hand, firm 1 is private, so it seeks to maximize its profit function (6). Thus, its reaction function is (18) as can be seen in Subsection 4.1. From the interception of reaction functions (11) and (18), the prices in the second stage of the game are obtained:

$$
p_{0}=\frac{1+\mu-2 \alpha_{0} \mu}{3(1-\mu)} ; p_{1}=\frac{2-\mu-\alpha_{0} \mu}{3(1-\mu)} .
$$

Notice that these prices satisfy $p_{0} \leq p_{1}$. By incorporating these prices (29) in the welfare function (9), the social welfare of Region 0 evaluated at the first stage of this game can be found, i.e.:

$$
W_{0}\left(\alpha_{0}\right)=\frac{36 v \mu(1-\mu)-4 \mu \alpha_{0}\left(1-5 \mu+2 \mu \alpha_{0}\right)+4-13 \mu+\mu^{2}}{72(1-\mu)} .
$$

In order to maximize the Region 0's welfare, the government of Region 0 does not take a stake in firm 0 when that region is relatively small enough, $\mu \leq 1 / 5$, otherwise, it only takes a partial stake. This result is consistent with that obtained in Section 6 and is summarized in the following proposition.

\footnotetext{
${ }^{6}$ The red area contains $F^{R} \leq\left(F_{0}^{N}+F^{P}\right) / 2$ and $F^{R}>F_{0}^{N}$. So $F^{R} \leq\left(F_{0}^{N}+F^{P}\right) / 2<\left(F^{R}+F^{P}\right) / 2$. Thus, $F^{R}<F^{P}$.
} 
Proposition 8 In the SPE of the Regional Mixed Duopoly in which regional partially publicly-owned firm 0 competes against private firm 1 (R0), the government of Region 0 fully privatizes firm 0 if $\mu \leq 1 / 5$; otherwise, it partially privatizes firm 0 , so that $\alpha_{0}^{R 0}=(5 \mu-1) / 4 \mu .^{7}$ Therefore, the same equilibrium is found as in the Private Duopoly when $\mu \leq 1 / 5$; otherwise, the prices, indifferent consumer and social welfare are as follows:

$$
\begin{aligned}
p_{0}^{R 0} & =\frac{1}{2} ; p_{1}^{R 0}=\frac{3}{4} ; \widehat{x}^{R 0}=\frac{5}{8} ; \pi_{0}^{R 0}=\frac{3 \mu+1}{16} ; \pi_{1}^{R 0}=\frac{9(1-\mu)}{32} ; C S_{0}^{R 0}=\frac{\mu(4 v-3)}{8} ; C S_{1}^{R 0}=\frac{(1-\mu)(32 v-31)}{64} ; \\
C S^{R 0} & =\frac{32 v+7 \mu-31}{64} ; W_{0}^{R 0}=\frac{8 v \mu-3 \mu+1}{16} ; W_{1}^{R 0}=\frac{(1-\mu)(32 v-13)}{64} ; W^{R 0}=\frac{32 v+\mu-9}{64} .
\end{aligned}
$$

Proof: see Appendix.

Unlike the case of the regional duopoly, the government of Region 0 does not fully own firm 0 , which implies that firms set different prices. The setting of a lower price by firm 0 causes some consumers in Region 1 buy from firm 0 since $\widehat{x}^{R 0}>1 / 2$, as in the Private Duopoly. These effects generate a welfare loss because they increase transport costs of consumers. The welfare of the country is also found to depend positively on the relative size of Region $0, \mu$. This is because a higher $\mu$ implies a lower proportion of consumers from Region 1 who buy from firm $0,{ }^{8}$ which reduces the consumers' disutility from not buying at their own location. This effect entails a welfare improvement that comes from a redistribution of market shares between firms.

From Figure 5, it can be observed that a lower size gap implies a higher regional government stake in firm 0 . Section 6 below shows that Region 0 prefers the private duopoly because of the aggressive price strategy by firms, especially by firm 0 . This is mainly explained by the fact that Region 0's consumers can buy cheaper products without assuming higher transport costs in the private duopoly. Moreover, the price strategy becomes more aggressive when the size gap is bigger. Thus, it is not counterintuitive for the government of Region 0 to fully privatize firm 0 when the size gap is big enough (in particular, $\mu \leq 1 / 5)$, as can be seen in Figure 5. On the other hand, when the size gap is low enough $(\mu \geq 1 / 5)$ the government of Region 0 decides to take a bigger stake in firm 0 as the gap decreases because the firm's price strategy becomes less aggressive.

\subsection{Private Firm 0 vs. Regional Publicly-owned Firm 1 (R1)}

Now consider the case where the government of Region 1 takes a stake in firm 1, so firm 1's aim is to maximize the objective function $\Pi_{1}=\alpha_{1} W_{1}+\left(1-\alpha_{1}\right) \pi_{1}$, where $\alpha_{1}$ represents the share of the government of Region 1 in firm 1 . This firm competes against the private firm 0 . The timing of the game is: i) the government of Region 1 chooses the stake in firm 1 that maximizes the social welfare of Region 1; and finally ii) firms simultaneously set prices. This game is now solved by backward induction.

Since firm 0 is private, it seeks to maximize its profit function (5). Thus, its reaction function is (22), as can be seen in Subsection 4.2. On the other hand, firm 1's aim is to maximize the objective function

\footnotetext{
$7 \lim _{\mu \rightarrow 1 / 2} \frac{5 \mu-1}{4 \mu}=\frac{3}{4}$.

$8 \frac{\partial\left(\widehat{x}^{R 0}\right)}{\partial \mu} \leq 0$
} 


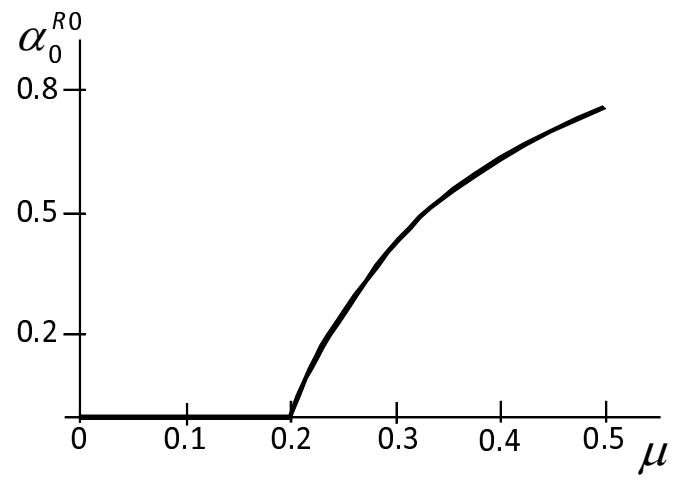

Figure 5: Region 0's stake in firm 0.
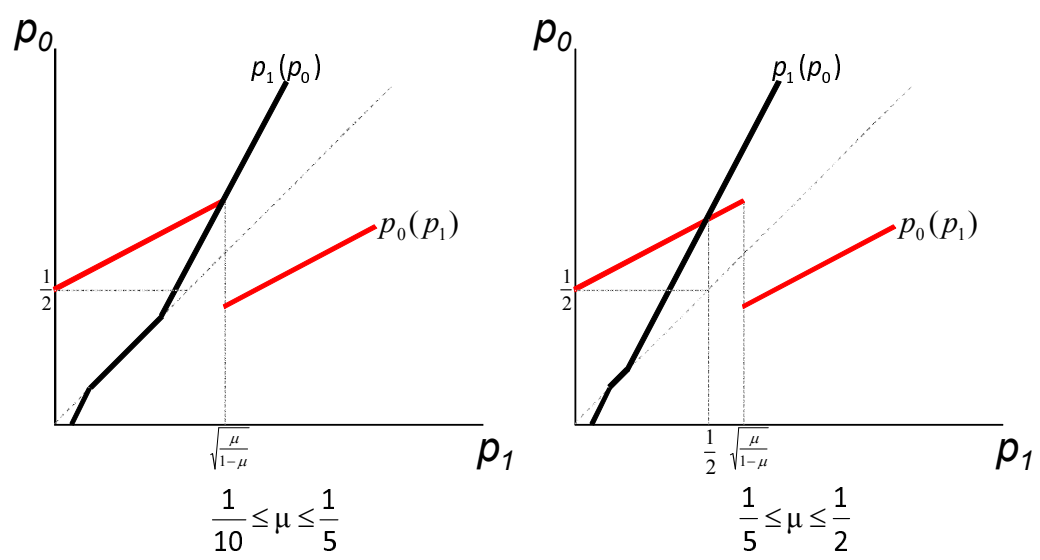

Figure 6: Regional Mixed Duopoly R1.

$\Pi_{1}$, as in the Regional Duopoly, so its reaction function is (12). From the interception of these reaction functions, the following price levels are obtained:

$$
p_{0}=\left\{\begin{array}{ll}
\frac{1-\alpha_{1}+\mu}{(1-\mu)\left(3-\alpha_{1}\right)} & \text { if } \alpha_{1} \leq \frac{1-2 \mu}{1-\mu} \\
\frac{1-\alpha_{1}+\mu+\mu \alpha_{1}}{3 \mu} & \text { if } \alpha_{1} \geq \frac{1-2 \mu}{1-\mu}
\end{array} ; p_{1}=\left\{\begin{array}{cl}
\frac{(2-\mu)\left(1-\alpha_{1}\right)}{(1-\mu)\left(3-\alpha_{1}\right)} & \text { if } \alpha_{1} \leq \frac{1-2 \mu}{1-\mu} \\
\frac{2-\mu-2 \alpha_{1}(1-\mu)}{3 \mu} & \text { if } \alpha_{1} \geq \frac{1-2 \mu}{1-\mu} .
\end{array}\right.\right.
$$

By incorporating these prices into the welfare function (10), the social welfare of Region 1 evaluated at the first stage of this game can be found, i.e.:

$$
W_{1}\left(\alpha_{1}\right)=\left\{\begin{array}{cl}
\frac{4 v(1-\mu)^{2}\left(3-\alpha_{1}\right)^{2}+18 \alpha_{1}+30 \mu-7 \alpha_{1}^{2}-9 \mu^{2}-3 \alpha_{1}^{2} \mu^{2}-32 \alpha_{1} \mu+10 \alpha_{1} \mu^{2}+10 \alpha_{1}^{2} \mu-15}{8(1-\mu)\left(3-\alpha_{1}\right)^{2}} & \text { if } \alpha_{1} \leq \frac{1-2 \mu}{1-\mu} \\
\frac{36 v \mu(1-\mu)+16 \alpha_{1}+11 \mu-8 \alpha_{1}^{2}+\mu^{2}-8 \alpha_{1}^{2} \mu^{2}-36 \alpha_{1} \mu+20 \alpha_{1} \mu^{2}+16 \alpha_{1}^{2} \mu-8}{72 \mu} & \text { if } \alpha_{1} \geq \frac{1-2 \mu}{1-\mu} .
\end{array}\right.
$$

In order to maximize Region 1's welfare, the government of Region 1 takes a partial stake in firm 1, which contrasts with the result obtained in the Regional Duopoly, in which the regional government fully owns firm 1. This result is summarized in Proposition 9. 
Proposition 9 An SPE of the Regional Mixed Duopoly in which regional partially publicly-owned firm 1 competes against private firm 0 (R1) exists if and only if $\mu \geq 1 / 10$. In the SPE of the game the government of Region 1 decides to take a partial stake in firm 1, so the regional government's stake, the prices, indifferent consumer and social welfare are ${ }^{9}$

i) if $\frac{1}{10} \leq \mu \leq \frac{1}{5}$,

$$
\begin{aligned}
\alpha_{1}^{R 1} & =\frac{2-\mu-3 \mu \sqrt{\frac{\mu}{1-\mu}}}{2(1-\mu)} ; p_{0}^{R 1}=\frac{1}{2}+\frac{\sqrt{\mu}}{2 \sqrt{1-\mu}} ; p_{1}^{R 1}=\sqrt{\frac{\mu}{1-\mu}} ; \widehat{x}^{R 1}=\frac{1}{4}+\frac{\sqrt{\mu}}{4 \sqrt{1-\mu}} ; \\
\pi_{0}^{R 1} & =\frac{\mu}{8}\left(1+\sqrt{\frac{\mu}{1-\mu}}\right)^{2} ; \pi_{1}^{R 1}=\frac{1}{4} \sqrt{\frac{\mu}{1-\mu}}\left(2-\mu-\mu \sqrt{\frac{\mu}{1-\mu}}\right) ; \\
C S_{0}^{R 1} & =\frac{\mu}{16}\left(8 v-6+\frac{1}{1-\mu}-6 \sqrt{\frac{\mu}{1-\mu}}\right) ; C S_{1}^{R 1}=\frac{1-\mu}{8}\left(4 v-1-4 \sqrt{\frac{\mu}{1-\mu}}\right) ; \\
C S^{R 1} & =\frac{1}{16}\left(8 v-2-8 \sqrt{\frac{\mu}{1-\mu}}+\mu\left(\frac{1}{1-\mu}-4+2 \sqrt{\frac{\mu}{1-\mu}}\right)\right) ; W_{0}^{R 1}=\frac{\mu}{16}\left(8 v-6+\frac{3}{1-\mu}-2 \sqrt{\frac{\mu}{1-\mu}}\right) ; \\
W_{1}^{R 1} & =\frac{1}{8}\left(4 v+1-\frac{2}{1-\mu}+\mu\left(3-4 v+2 \sqrt{\frac{\mu}{1-\mu}}\right)\right) ; W^{R 1}=\frac{1}{16}\left(8 v-1-\frac{1}{1-\mu}+2 \mu \sqrt{\frac{\mu}{1-\mu}}\right) . \\
\text { if } \frac{1}{5} & \leq \mu<\frac{1}{2},
\end{aligned}
$$$$
\begin{aligned}
\alpha_{1}^{R 1} & =\frac{4-5 \mu}{4-4 \mu} ; p_{0}^{R 1}=\frac{3}{4} ; p_{1}^{R 1}=\frac{1}{2} ; \widehat{x}^{R 1}=\frac{3}{8} ; \pi_{0}^{R 1}=\frac{9 \mu}{32} ; \pi_{1}^{R 1}=\frac{4-3 \mu}{16} ; \\
C S_{0}^{R 1} & =\frac{\mu(32 v-31)}{64} ; C S_{1}^{R 1}=\frac{(1-\mu)(4 v-3)}{8} ; C S^{R 1}=\frac{32 v-7 \mu-24}{64} ; \\
W_{0}^{R 1} & =\frac{\mu(32 v-13)}{64} ; W_{1}^{R 1}=\frac{8 v(1-\mu)+3 \mu-2}{16} ; W^{R 1}=\frac{32 v-\mu-8}{64} .
\end{aligned}
$$

Notice that the government of Region 1 partially privatizes the firm located in its region, so it sets the lowest prices, which contrasts with the results of the other duopolies. Thus, the regional partially publiclyowned firm 1 sells to some consumers in Region 0, which generates a welfare loss because it increases the transport costs of those consumers since they buy from the firm furthest from their location. In addition, a smaller size gap (a higher $\mu$ ) implies a higher private incentive for firm 1 to sell to consumers located in Region 0 . Thus, it is less necessary for the regional government to intervene in firm 1 in order to improve welfare in Region 1, i.e. the stake taken by the government of Region 1 in firm 1 decreases as $\mu$ increases, as can be seen in Figure 7 .

\subsection{Regional Publicly-owned Firm 0 vs. National Publicly-owned Firm 1 (RoN)}

This subsection examines the case where the government of Region 0 takes a stake in firm 0 , so firm 0 's aim is to maximize the objective function $\Pi_{0}=\alpha_{0} W_{0}+\left(1-\alpha_{0}\right) \pi_{0}$, while the national government takes a stake in firm 1, so firm 1's aim is to maximize the objective function $\Pi_{1}=\alpha W+(1-\alpha) \pi_{1}$. The timing of the game is: i) the national and regional governments simultaneously choose their stakes in firms 1

\footnotetext{
${ }^{9}$ The condition $\mu \geq 1 / 5$ ensures that $p_{1}^{R 1}=\frac{1}{2} \leq \sqrt{\frac{\mu}{1-\mu}}$, and, the condition $\mu \geq 1 / 10$ ensures that $\alpha_{1}^{R 1} \leq 1$.
} 


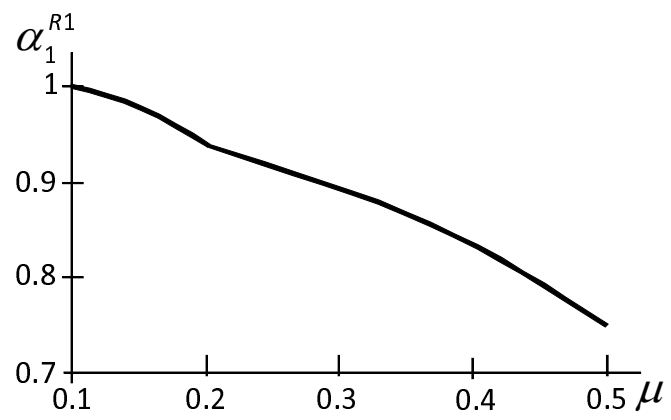

Figure 7: Regional 1's stake in firm 1.

and 0 , respectively; and finally ii) firms simultaneously set prices. This game is now solved by backward induction.

From the Regional Duopoly it is known that regional firm 0's reaction function is (11), and from the National Mixed Duopoly it is known that national firm 1's reaction function is (21). In the interception of these reaction functions, the following price levels are obtained:

$$
p_{0}=\frac{1-\alpha-\mu \alpha_{0}(2-\alpha)+\mu}{(1-\mu)(3-2 \alpha)} ; p_{1}=\frac{2-2 \alpha-\mu+2 \alpha \mu-\mu \alpha_{0}}{(1-\mu)(3-2 \alpha)} .
$$

Notice that $p_{0} \leq p_{1}$. By incorporating these prices into the welfare functions (9) and (15), the welfare of Region 0 and the country evaluated at the first stage of this game can be found, i.e.:

$$
\begin{aligned}
W_{0} & =\frac{\mu(4 v-1)}{8}+\frac{(1-\alpha)\left(1-2 \mu+\mu \alpha_{0}\right)\left(1-\alpha+\mu-2 \mu \alpha_{0}+\alpha \mu \alpha_{0}\right)}{2(1-\mu)(3-2 \alpha)^{2}} \\
W & =\frac{4 v-1}{8}-\frac{2\left(1-2 \mu+\mu \alpha_{0}\right)^{2}(1-\alpha)^{2}}{8(1-\mu)(3-2 \alpha)^{2}}
\end{aligned}
$$

The government of Region 0 chooses the $\alpha_{0}$ that maximizes $W_{0}$, and the national government chooses the $\alpha$ that maximizes $W$. Thus, the reaction functions of the two governments are:

$$
\alpha_{0}(\alpha)=\frac{5 \mu-1-2 \alpha \mu}{2 \mu(2-\alpha)} ; \alpha\left(\alpha_{0}\right)=1
$$

From the interception of the above function it is obtained that the government of Region 0 takes a partial stake in firm $0\left(\alpha_{0}=(3 \mu-1) / 2 \mu\right)$, while the national government fully nationalizes firm 1 . However, the price reaction functions of the two firms do not intercept, as can be seen in Figure 8, which implies that there is no SPE in this regional mixed duopoly. This kind of regional mixed duopoly is therefore not considered in the rest of this study.

Proposition 10 In the Regional Mixed Duopoly RON there is no SPE.

Proof: see Appendix. 

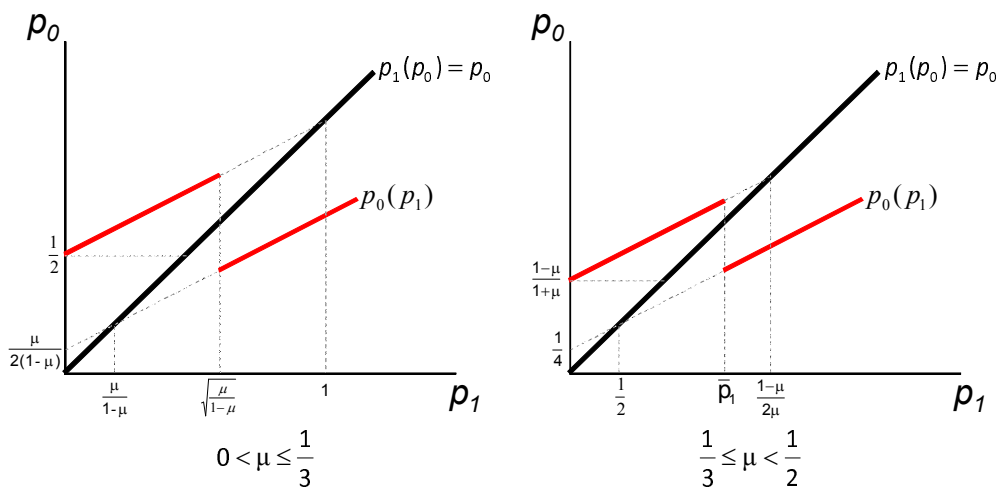

Figure 8: Regional Mixed Duopoly R0N.

\subsection{National Publicly-owned Firm 0 vs. Regional Publicly-owned Firm 1 (R1N)}

The government of Region 1 takes a stake in firm 1, so firm 1's aim is to maximize the objective function $\Pi_{1}=\alpha_{1} W_{1}+\left(1-\alpha_{1}\right) \pi_{1}$, and the national government takes a stake in firm 0 , so firm 0 's aim is to maximize the objective function $\Pi_{0}=\alpha W+(1-\alpha) \pi_{0}$. The timing of the game is: i) the national and regional governments simultaneously choose their stakes in firms 0 and 1 , respectively; and finally ii) the two firms simultaneously set prices. This game is now solved by backward induction.

As can be seen in the National Mixed Duopoly, firm 0's reaction function is (17), and in the Regional Duopoly firm 1's reaction function is (12). From the interception of these reaction functions, the following price levels are obtained:

$$
p_{0}=\left\{\begin{array}{cl}
\frac{\mu-2 \alpha \mu-\alpha_{1}+\alpha \mu \alpha_{1}+1}{\left(3-2 \alpha-\alpha_{1}+\alpha \alpha_{1}\right)(1-\mu)} & \text { if } \alpha_{1} \leq \frac{1-2 \mu}{1-\mu} \\
\frac{\mu-2 \alpha \mu+1-\alpha_{1}+\mu \alpha_{1}}{\mu(3-2 \alpha)} & \text { if } \alpha_{1} \geq \frac{1-2 \mu}{1-\mu}
\end{array} ; p_{1}= \begin{cases}\frac{\left(1-\alpha_{1}\right)(2-\alpha-\mu)}{\left(3-2 \alpha-\alpha_{1}+\alpha \alpha_{1}\right)(1-\mu)} & \text { if } \alpha_{1} \leq \frac{1-2 \mu}{1-\mu} \\
\frac{\left(1-\alpha_{1}+\mu \alpha_{1}\right)(2-\alpha)-\mu}{\mu(3-2 \alpha)} & \text { if } \alpha_{1} \geq \frac{1-2 \mu}{1-\mu}\end{cases}\right.
$$

By incorporating these prices into the welfare functions (10) and (15), the social welfare of Region 1 and of the country evaluated at the first stage of this game is obtained, i.e.:

$$
\begin{gathered}
W_{1}=\left\{\begin{array}{cl}
\frac{(1-\mu)(4 v-1)}{8}-\frac{2\left(3-\alpha-3 \alpha_{1}-2 \alpha \mu+\alpha \alpha_{1}+\mu \alpha_{1}+\alpha \mu \alpha_{1}\right)\left(1-2 \mu-\alpha_{1}+\mu \alpha_{1}\right)(1-\alpha)}{8(1-\mu)\left(-2 \alpha-\alpha_{1}+\alpha \alpha_{1}+3\right)^{2}} & \text { if } \alpha_{1} \leq \frac{1-2 \mu}{1-\mu} \\
\frac{(1-\mu)(4 v-1) \mu(2 \alpha-3)^{2}-4(1-\alpha)\left(1-2 \mu-\alpha_{1}+\mu \alpha_{1}\right)\left(\alpha \alpha_{1}-\mu-2 \alpha_{1}-\alpha+2 \mu \alpha_{1}-\alpha \mu \alpha_{1}+2\right)}{8 \mu(3-2 \alpha)^{2}} & \text { if } \alpha_{1} \geq \frac{1-2 \mu}{1-\mu}
\end{array}\right. \\
W= \begin{cases}\frac{4 v-1}{8}+\frac{2(1-\alpha)^{2}\left(1-2 \mu-\alpha_{1}+\mu \alpha_{1}\right)^{2}}{8(\mu-1)\left(3-2 \alpha-\alpha_{1}+\alpha \alpha_{1}\right)^{2}} & \text { if } \alpha_{1} \leq \frac{1-2 \mu}{1-\mu} \\
\frac{4 v-1}{8}-\frac{2(1-\alpha)^{2}\left(1-2 \mu-\alpha_{1}+\mu \alpha_{1}\right)^{2}}{8 \mu(3-2 \alpha)^{2}} & \text { if } \alpha_{1} \geq \frac{1-2 \mu}{1-\mu}\end{cases}
\end{gathered}
$$

The national government chooses the $\alpha$ that maximizes $W$, and the government of Region 1 chooses the $\alpha_{1}$ that maximizes $W_{1}$. Thus, the reaction functions of the two governments are:

$$
\alpha\left(\alpha_{1}\right)=1 ; \alpha_{1}(\alpha)=\left\{\begin{array}{cl}
\frac{3-\alpha-3 \mu}{3-\alpha-2 \mu} & \text { if } \alpha_{1} \leq \frac{1-2 \mu}{1-\mu} \\
\frac{4-2 \alpha-5 \mu+2 \alpha \mu}{4-2 \alpha-4 \mu+2 \alpha \mu} & \text { if } \alpha_{1} \geq \frac{1-2 \mu}{1-\mu}
\end{array}\right.
$$




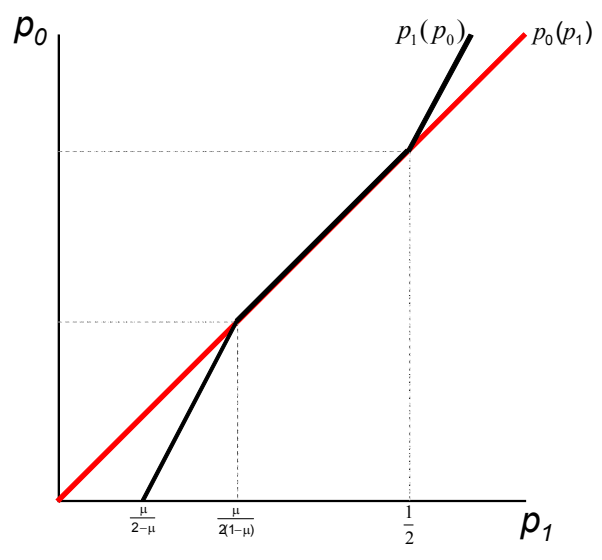

Figure 9: Regional Mixed Duopoly R1N.

As can be seen in Proposition 11, the government of Region 1 takes a partial stake in firm 1 and the national government fully nationalizes firm $0 .{ }^{10}$ This result contrasts with that obtained in previous literature by Tomaru and Nakamura (2012), who obtain that when the national and regional governments independently consider whether to privatize their respective public firms, only the state-owned public firm should be privatized. ${ }^{11}$ Moreover, I find that there is a multiplicity of equilibrium prices, as in the national mixed duopoly.

Proposition 11 In the SPE of the Regional Mixed Duopoly R1N, the national government fully controls firm 0 and the government of Region 1 decides to take a partial stake in firm 1, so the regional government's stakes, prices, the indifferent consumer and social welfare are: ${ }^{12}$

$$
\begin{aligned}
\alpha^{R 1 N} & =1 ; \alpha_{1}^{R 1 N}=\frac{2-3 \mu}{2(1-\mu)} ; p_{0}^{R 1 N}=p_{1}^{R 1 N}=p^{R 1 N} \in\left[\frac{\mu}{2(1-\mu)}, \frac{1}{2}\right] ; \widehat{x}^{R 1 N}=\frac{1}{2} ; \pi_{0}^{R 1 N}=\frac{\mu p^{R 1 N}}{2} ; \\
\pi_{1}^{R 1 N} & =\frac{(1-\mu) p^{R 1 N}}{2} ; C S_{0}^{R 1 N}=\frac{\mu\left(4 v-4 p^{R 1 N}-1\right)}{8} ; C S_{1}^{R 1 N}=\frac{(1-\mu)\left(4 v-4 p^{R 1 N}-1\right)}{8} ; \\
C S^{R 1 N} & =\frac{4 v-4 p^{N R}-1}{8} ; W_{0}^{R 1 N}=\mu \frac{4 v-1}{8} ; W_{1}^{R 1 N}=(1-\mu) \frac{4 v-1}{8} ; W^{R 1 N}=\frac{4 v-1}{8}
\end{aligned}
$$

The government of Region 1 partially privatizes firm 1 but it does not set a lower price than firm 0 , as in the regional mixed duopoly R1. This is because of the full control of firm 0 by the national government, which tries to avoid the welfare loss generated by consumers' disutility from not buying from the nearest firm. Thus, in equilibrium, both firms set the same prices and the maximum social welfare level is achieved, as in the National Mixed Duopoly and the Regional Duopoly.

As in the previous regional mixed duopolies, the government of Region 1 increases its stake in firm 1 as the relative size of Region 1 increases. The intuition behind this is that a bigger Region 1 reduces the

\footnotetext{
${ }^{10}$ Notice that $\alpha_{1}^{R 1 N}=\frac{2-3 \mu}{2(1-\mu)}>\frac{1-2 \mu}{1-\mu}$.

${ }^{11}$ Tomaru and Nakamura (2012) develop a mixed oligopoly model with quantity competition, in which firms produce a homogenous good and governments do not consider the option of partial privatization.

${ }^{12}$ Given that $\alpha^{R 1 N}=1$, there is no discontinuity in $p_{0}\left(p_{1}\right)$. Thus, the two price reaction functions always intercept.
} 


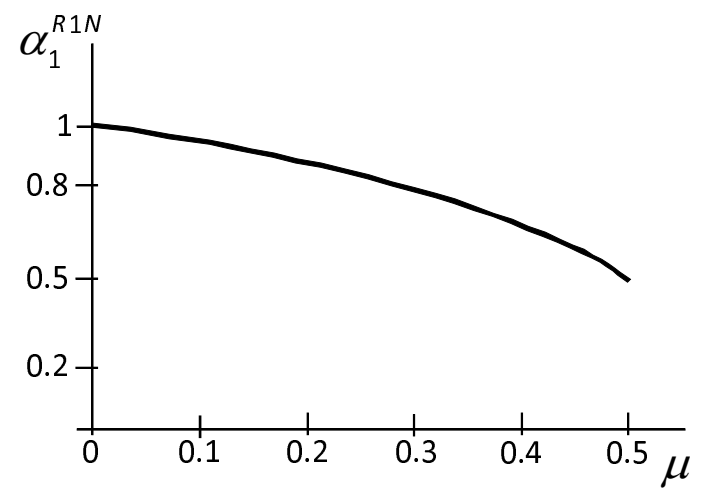

Figure 10: Regional 1's stake in firm 1.

incentive of private firm 1 to compete for new consumers, but increases the incentives of private firm 0 . These firms' reactions entail that some consumers of Region 1 can buy from firm 0 , which generates a social loss in Region 1 because it increases the transport cost of consumers when they buy from the firm furthest away. Thus, when the relative size of Region 1 increases, the government of Region 1 must take a bigger stake in firm 1 to avoid increasing the transport cost of consumers located in that region, as can be seen in Figure 10.

Given that $p_{0}^{R 1 N}=p_{1}^{R 1 N}=1 / 2$ is an equilibrium for all values of $\mu$, these equilibrium prices for the regional mixed duopoly R1N are considered in the following section, which compares the equilibria of the different market structures. This assumption only affects the consumer surplus and profit comparisons.

\section{Social Welfare Analysis}

By comparing the social welfare obtained in the duopolies considered above, the following relationship between them is found:

$$
\begin{aligned}
& W^{R 0} \leq W^{P} \leq W^{R 1}<W^{N}=W^{R 1 N}=W^{R} \text { if } \mu \leq \frac{1}{2}-\frac{3 \sqrt{73}}{146} \\
& W^{R 0}<W^{R 1} \leq W^{P}<W^{N}=W^{R 1 N}=W^{R} \text { if } \mu \geq \frac{1}{2}-\frac{3 \sqrt{73}}{146}
\end{aligned}
$$

From the relationship (35), it can be concluded that (national or regional) public intervention is essential for the social optimum to be achieved, because the private duopoly provides lower welfare than the social optimum. However, it is not the worst market structure from the social welfare viewpoint when mixed regional duopolies are considered in the analysis of social welfare. The market structure that provides the lowest welfare is the regional mixed duopoly in which the government of Region 0 fully owns firm 0 , while firm 1 is private (R0). The intuition is that the regional mixed duopoly R0 provides the lowest social welfare for Region 1, as can be seen in (39), and this region is more densely populated 
than Region 0. On the other hand, there are several ways to attain the social optimum, as specified in the following proposition:

Proposition 12 The market structures that achieve the social optimum are:

i) each regional government fully controls the firm located in its region (Regional Duopoly);

ii) the government of Region 1 partially owns firm 1, while the national government fully owns firm 0 (Regional Mixed Duopoly R1N); and,

iii) the national government fully owns firm 0, while firm 1 is private (National Mixed Duopoly).

A striking result is that the full ownership of firm 0 by the national government ensures that the social optimum is achieved independently of the ownership of firm 1 (private or public). Thus, regional government intervention in firm 1 is not necessary in order to achieve the social optimum.

As can be seen from the relationships (36) and (37), the preferences of consumers and firms about market structures are completely opposite. ${ }^{13}$ For instance, the national mixed duopoly is the best outcome for firms, but the worst for consumers, while the regional duopoly is the best outcome for consumers and the worst outcome for firms. The regional mixed duopolies provide intermediate levels of consumer and producer surpluses. However, those regional mixed duopolies in which one firm is private are worse from the consumers' perspective, but better from the producers' perspective.

$$
\begin{gathered}
C S^{N}<C S^{P} \leq C S^{R 0}<C S^{R 1 N}<C S^{R 1}<C S^{R} \text { if } \mu \leq 0.1741889 \\
C S^{N}<C S^{P} \leq C S^{R 0}<C S^{R 1}<C S^{R 1 N}<C S^{R} \text { if } \mu \geq 0.1741889 \\
\pi^{R}<\pi^{R 1} \leq \pi^{R 1 N}<\pi^{R 0} \leq \pi^{P}<\pi^{N} \text { if } \mu \leq 0.17788 \\
\pi^{R}<\pi^{R 1 N} \leq \pi^{R 1}<\pi^{R 0} \leq \pi^{P}<\pi^{N} \text { if } \mu \geq 0.17788
\end{gathered}
$$

Two interesting and logical results are obtained from (38) and (39). First, in each region, the social welfare is maximized when the regional government fully controls the firm in its region and the rival firm is private. Second, the regional welfare is minimized when the firm in the region is private and the rival firm is fully owned by the government of the neighboring region. These results are in line with those obtained by Bárcena-Ruiz and Garzón (2005b), who analyze a quantity competition model with homogenous goods, where the governments decide whether to privatize a public firm or not. They obtain that when the marginal cost of the publicly-owned firms takes an intermediate value, each government wants it to be the government of the other country that privatizes its publicly-owned firm. In this case, the latter government obtains lower social welfare than the other. Finally, I find that the regional mixed duopoly R1N provides the same welfare as the national mixed and regional duopolies in each region.

$$
W_{0}^{R 1}<W_{0}^{R}=W_{0}^{R 1 N}=W_{0}^{N}<W_{0}^{P} \leq W_{0}^{R 0}
$$

\footnotetext{
${ }^{13} \pi^{j}=\pi_{0}^{j}+\pi_{1}^{j}$ is defined as the producer surplus in market structure $j=R, N, P, R 0, R 1, R 1 N$.
} 


$$
W_{1}^{R 0} \leq W_{1}^{P}<W_{1}^{R}=W_{1}^{R 1 N}=W_{1}^{N}<W_{1}^{R 1}
$$

Notice that the private duopoly ceases to be the best outcome for the Region 0 . This is because the consumer surplus is higher in Region 0 in the regional mixed duopoly R0, as can be seen in (40). Moreover, from relationships (40) and (41), it can be seen that the regional duopoly maximizes the consumer surpluses in both regions, while the national mixed duopoly minimizes it. This is because firms set a price of zero in the regional duopoly, while they set the highest prices in the national mixed duopoly.

$$
\begin{aligned}
C S_{0}^{N}< & C S_{0}^{R 1}<C S_{0}^{R 1 N} \leq C S_{0}^{P}=C S_{0}^{R 0}<C S_{0}^{R} \text { if } \mu \leq \frac{1}{5} \\
C S_{0}^{N}< & C S_{0}^{R 1} \leq C S_{0}^{P} \leq C S_{0}^{R 1 N}=C S_{0}^{R 0}<C S_{0}^{R} \text { if } \frac{1}{5} \leq \mu \leq \frac{37}{101} \\
C S_{0}^{N}< & C S_{0}^{P} \leq C S_{0}^{R 1}<C S_{0}^{R 1 N}=C S_{0}^{R 0}<C S_{0}^{R} \text { if } \frac{37}{101} \leq \mu \\
& C S_{1}^{N}<C S_{1}^{P} \leq C S_{1}^{R 0}<C S_{1}^{R 1 N} \leq C S_{1}^{R 1}<C S_{1}^{R}
\end{aligned}
$$

\section{Conclusions}

In this paper I analyze the privatization policies implemented by national and regional governments by considering a horizontal differentiation model with price competition in which a country is divided into two regions. Following Gabszewicz and Wauthy (2012), I assume that those regions are of different sizes. An underlying overall conclusion of this paper is that the relative size of the regions is an important feature in the design of the privatization policies implemented by national and regional governments.

My analysis shows that public intervention by either the national or regional government is essential for achieving the social optimum. Thus, there are several ways to attain the social optimum: i) the firm located in the less populated region, firm 0 , is fully controlled by the national government while the firm located in more populated region, firm 1, is private (national mixed duopoly); ii) each firm is owned by the government of the region where it is located (regional duopoly); and iii) firm 0 is owned by the national government while firm 1 is partially owned by the government of the region where it is located (regional mixed duopoly R1N). The private duopoly does not achieve the social optimum because it increases the consumers' disutility from not buying from the nearest firm. However, not all public interventions in firms are better than the private duopoly. For instance, the market structure in which the government of the less populated region takes a stake in firm 0 and firm 1 is private provides the lowest social welfare, and when the two regions are similar enough in size the market structure in which the government of the more populated region takes a stake in firm 1 and firm 0 is private also provides lower social welfare than the private duopoly.

An interesting result is that the preferences of consumers and firms about market structures are completely opposite. For instance, the national mixed duopoly is the best outcome for firms but the worst for consumers, while the regional duopoly is the best outcome for consumers and the worst outcome for firms. In addition, regional governments have higher incentives to control the firm located at their region as the relative size of that region increases. The intuition behind this is that a bigger region reduces the 
incentives of the private firm in the region to compete for new consumers, but increases the incentives of the rival firm located in the neighboring region. These firms' reactions generate a social loss because they increase the disutility of the consumers of the region from not buying from the nearest firm. Thus, when the relative size of a region increases, the regional government must take a bigger stake in the firm located in that region.

Finally, from a regional perspective, social welfare in each region is maximized when the regional government fully controls the firm in its region and the rival firm is private, while regional welfare is minimized when the firm in the region is private and the rival firm is fully owned by the government of the neighboring region. These results are in line with those of Bárcena-Ruiz and Garzón (2005b), who analyze an oligopoly model with quantity competition and homogenous goods where governments decide whether to privatize a public firm or not.

\section{Appendix}

Proof of Proposition 8. Firm 1 is private, so its reaction function is (18), which is continuous. On the other hand, firm 0 is fully privatized if $\mu \leq \frac{1}{5}$ because of $\alpha_{0}^{R 0}=0$, so its reaction function is (22), which is discontinuous at $p_{1}=\sqrt{\frac{\mu}{1-\mu}}$. Given that $p_{1}^{P}=\frac{2-\mu}{3(1-\mu)}>\sqrt{\frac{\mu}{1-\mu}}$, it is obtained that the two reaction functions intercept, so the equilibrium exists as in the private duopoly (see Gabszewicz and Wauthy (2012) for more details). If $\mu \geq \frac{1}{5}$, firm 0 is partially privatized because of $\alpha_{0}^{R 0}=\frac{5 \mu-1}{4 \mu}$. Thus, its reaction function is

$$
p_{0}\left(p_{1}\right)=\left\{\begin{array}{cl}
\frac{1}{8}+\frac{p_{1}}{2} & \text { if } p_{0} \leq p_{1} \\
\left(p_{1}+1\right)\left(\frac{1-\mu}{3 \mu+1}\right) & \text { if } p_{0} \geq p_{1}
\end{array}\right.
$$

which is discontinuous at $\widetilde{p}_{1}=\frac{\mu(6-5 \mu)-1-2 \sqrt{2} \sqrt{(1-\mu)(1+3 \mu)(1-2 \mu)^{2}}}{44 \mu^{2}-8 \mu-4}$. Given that $p_{1}^{R 0}=\frac{3}{4}>\widetilde{p}_{1}$, it is obtained that the two reaction functions intercept, so the equilibrium exists.

Proof of Proposition 10. From the interception of the reaction functions for the stakes of the government of Region 0 and the national government, (34), the following is obtained:

$$
\alpha_{0}=\left\{\begin{array}{cl}
0 & \text { if } \mu \leq \frac{1}{3} \\
\frac{3 \mu-1}{2 \mu} & \text { if } \mu \geq \frac{1}{3}
\end{array} ; \alpha=1 .\right.
$$

Case I: $\mu \leq 1 / 3$. Notice that firm 0 is private, so the price reaction functions of firm 0 is (22). The price reaction function of firm 1 is $p_{1}\left(p_{0}\right)=p_{0}$. Given that $\frac{\mu}{2(1-\mu)}<\frac{1}{2}$ and $\frac{\mu}{1-\mu}<1$, the function (22) is discontinuous. By solving $\pi_{0}\left(\frac{\mu}{2(1-\mu)}+\frac{p_{1}}{2}, p_{1}\right)=\pi_{0}\left(\frac{1}{2}+\frac{p_{1}}{2}, p_{1}\right)$, it is obtained that it is discontinuous at $p_{1}=\sqrt{\frac{\mu}{1-\mu}} \in\left(\frac{\mu}{1-\mu}, 1\right)$. Given that $\frac{\mu}{1-\mu}<\sqrt{\frac{\mu}{1-\mu}}<1$, it is found that the functions (22) and $p_{1}\left(p_{0}\right)=p_{0}$ do not intercept. Therefore, there is no SPE when $\mu \leq 1 / 3$.

Case II: $\mu \geq 1 / 3$. Notice that firm 0 is partially privatized because of $\alpha_{0}=\frac{3 \mu-1}{2 \mu} \in[0,1)$, so the price reaction functions of firm 0 is

$$
p_{0}\left(p_{1}\right)=\left\{\begin{array}{cl}
\frac{1}{4}+\frac{p_{1}}{2} & \text { if } p_{0} \leq p_{1} \\
\left(p_{1}+1\right) \frac{1-\mu}{\mu+1} & \text { if } p_{0} \geq p_{1},
\end{array}\right.
$$


As in Case I, the price reaction function of firm 1 is $p_{1}\left(p_{0}\right)=p_{0}$. Given that $\frac{1}{4}<\frac{1-\mu}{\mu+1}$ and $\frac{1}{2}<\frac{1-\mu}{2 \mu}$, the function (42) is discontinuous. By solving $\Pi_{0}\left(\frac{1}{4}+\frac{p_{1}}{2}, p_{1}\right)=\Pi_{0}\left(\left(p_{1}+1\right) \frac{1-\mu}{\mu+1}, p_{1}\right)$, it is obtained that it is discontinuous at $\bar{p}_{1} \in\left[\frac{1}{2}, \frac{1-\mu}{2 \mu}\right]$. Thus, given that $p_{0}=p_{1}$ in the equilibrium, there are two equilibrium candidates: 1) $p_{0}^{1}=p_{1}^{1}=\frac{1}{2}$, and 2) $p_{0}^{2}=p_{1}^{2}=\frac{1-\mu}{2 \mu}$.

Equilibrium candidate 1) is now analyzed. If $p_{1}=\frac{1}{2}$, the partially publicly-owned firm 0 can set $p_{0}=\frac{1}{2}$ and obtain $\Pi_{0}\left(\frac{1}{2}, \frac{1}{2}\right)=\frac{12 v \mu-4 v-5 \mu+3}{16}$, or set the price $p_{0}=\frac{3(1-\mu)}{2(\mu+1)}$ and obtain $\Pi_{0}\left(\frac{3(1-\mu)}{2(\mu+1)}, \frac{1}{2}\right)=$ $\frac{8 v \mu-4 v-10 \mu+3 \mu^{2}+12 v \mu^{2}+5}{16(\mu+1)}$. Since $\Pi_{0}\left(\frac{1}{2}, \frac{1}{2}\right)<\Pi_{0}\left(\frac{3(1-\mu)}{2(\mu+1)}, \frac{1}{2}\right)$, the best response of firm 0 is to set $p_{0}=$ $\frac{3(1-\mu)}{2(\mu+1)}$ if $p_{1}=\frac{1}{2}$. Thus, $p_{0}^{1}=p_{1}^{1}=\frac{1}{2}$ is not an equilibrium.

Equilibrium candidate 2) is now analyzed. If $p_{1}=\frac{1-\mu}{2 \mu}$, the partially publicly-owned firm 0 can set $p_{0}=\frac{1-\mu}{2 \mu}$ and obtain $\Pi_{0}\left(\frac{1-\mu}{2 \mu}, \frac{1-\mu}{2 \mu}\right)=\frac{2-3 \mu-4 v \mu-\mu^{2}+12 v \mu^{2}}{16 \mu}$, or set the price $p_{0}=\frac{1}{4 \mu}$ and obtain $\Pi_{0}\left(\frac{1}{4 \mu}, \frac{1-\mu}{2 \mu}\right)=\frac{1-\mu+2 \mu^{2}-6 \mu^{3}-8 v \mu^{2}+24 v \mu^{3}}{32 \mu^{2}}$. Since $\Pi_{0}\left(\frac{1-\mu}{2 \mu}, \frac{1-\mu}{2 \mu}\right)<\Pi_{0}\left(\frac{1}{4 \mu}, \frac{1-\mu}{2 \mu}\right)$, the best response of firm 0 is to set $p_{0}=\frac{1}{4 \mu}$ if $p_{1}=\frac{1-\mu}{2 \mu}$. Thus, $p_{0}^{2}=p_{1}^{2}=\frac{1-\mu}{2 \mu}$ is not an equilibrium.

\section{References}

Aiura, H., 2013, Inter-regional competition and quality in hospital care, The European Journal of Health Economics, 14, pp. 515-526.

Aiura, H. and Y. Sanjo, 2010, Privatization of local public hospitals: Effect on budget, medical service quality, and social welfare, International Journal of Health Care Finance and Economics, 10, pp. 275-299.

Albalate, D., G. Bel and X. Fageda, 2012, Beyond pure public and pure private management models: Mixed firms in the European Airport Industry, IREA Working Papers 201221, University of Barcelona, Research Institute of Applied Economics.

Bárcena-Ruiz, J.C. and M.B. Garzón, 2005a, Economic Integration and Privatization under Diseconomies of Scale, European Journal of Political Economy, 21, pp. 247-267.

Bárcena-Ruiz, J.C. and M.B. Garzón, 2005b, International Trade and Strategic Privatization, Review of Development Economics, 9, pp. 502-513.

Bel, G. and L. Domènech, 2009, What Influences Advertising Price in Television Channels?: An Empirical Analysis on the Spanish Market, Journal of Media Economics, 22 (3), 164-183.

Benassi, C., A. Chirco and C. Colombo, 2006, Vertical Differentiation and the Distribution of Income, Bulletin of Economic Research, 58 (4), pp. 345-367.

Bortolotti, B. and M. Faccio, 2009, Government Control of Privatized Firms, Review of Financial Studies, 22 (8), pp. 2907-2939.

Bortolotti, B., M. Fantini and D. Siniscalco, 2003, Privatization Around the World: Evidence from Panel Data, Journal of Public Economics, 88 (1-2), pp. 305-332. 
Brekke, K. R., L. Siciliani and O. R. Straume, 2008, Competition and Waiting Times in Hospital Markets, Journal of Public Economics, 92 (7), pp. 1607-1628.

Calvó-Armengol, A. and Y. Zenou, 2002, The Importance of the Distribution of Consumers in Horizontal Product Differentiation, Journal of Regional Science, 42(4), pp. 793-803.

Cremer, H. and D. Maldonado, 2013, "Mixed Oligopoly in Education, IDEI Working Papers 766 Institut d'Économie Industrielle (IDEI), mimeo.

Cremer, H., M. Marchand and J.F. Thisse, 1991, Mixed Oligopoly with Differentiated Products, International Journal of Industrial Organization, 9 (1), pp. 43-53.

De Fraja, G. and F. Delbono, 1989, Alternative Strategies of a Public Enterprise in Oligopoly, Oxford Economic Papers, 41 (1), 302-311.

De Fraja, G. and P. Valbonesi, 2012, The Design of the University System, Journal of Public Economics, 96, pp. 317-330.

Gabszewicz, J. J. and X. Wauthy, 2012, Nesting Horizontal and Vertical Differentiation, Regional Science and Urban Economics, 42 (6), 998-1002.

González-Maestre, M. and F. Martínez-Sánchez, 2010, The Role of Program Quality and Publiclyowned Platforms in the Free to Air Broadcasting Industry, IVIE Working Papers Serie AD 2010-19.

González-Maestre, M. and F. Martínez-Sánchez, 2012, Quality Choice and Advertising Regulation in Broadcasting Markets, IVIE WP-AD 2012-03.

Inoue, T., Y. Kamijo and Y. Tomaru, 2009, Interregional Mixed Duopoly, Regional Science and Urban Economics, 39, 233-242.

Kumar, A. and B. Saha, 2008, Spatial Competition in a Mixed Duopoly with one Partially Nationalized Firm, Journal of Comparative Economics, 36 (2), 326-341.

Martínez-Sánchez, F., 2011, Bertrand Competition in a Mixed Duopoly Market: A Note, The Manchester School, 79 (6), 1058-1060.

Matsumura, T., 1998, Partial Privatization in Mixed Duopoly, Journal of Public Economics, 70 (3), 473-483.

Matsumura, T. and N. Matsushima, 2012, Airport Privatization and Interregional Competition, The Japanese Economic Review, 63 (4), pp. 431-450.

Sanjo, Y., 2009, Bertrand Competition in a Mixed Duopoly Market, The Manchester School, 77 (3), 373-397.

Takahashi, T., 2004, Spatial competition of governments in the investment on public facilities, Regional Science and Urban Economics, 34, 455-488.

Tomaru, Y. and Y. Nakamura, 2012, Inter-regional Mixed Oligopoly with a Vertical Structure of Government, Australian Economic Papers, 51, pp. 38-54. 